\title{
EDUCAÇÃO ESTÉTICA PELA LEITURA LITERÁRIA $^{1}$
}

\author{
AESTHETIC EDUCATION THROUGH LITERARY READING
}

Flávia Brocchetto Ramos

Doutora em Linguística e Letras pela PUC/RS. Docente do Programa de Pós-Graduação em Educação da UCS.

Taciana Zanolla

Graduada em Letras pelas UCS.

Programa de Pós-Graduação em Educação Universidade de Caxias do Sul (UCS)

Caxias do Sul - RS - Brasil

Endereço:

Rua Antonio Xavier da Luz, 710

Petrópolis - Caxias do Sul - RS

CEP: $95070-040$

E-mails:

ramos.fb@gmail.com

tacianazanolla@gmail.com

RESUMO

A presença da leitura literária na escola, visando à educação estética dos estudantes, é uma das metas do projeto Educação, Linguagem e Práticas leitoras II (UCS/CNPq), em virtude da importância da literatura para a formação humana. Contudo ela não é um componente curricular no Ensino Fundamental brasileiro e, no geral, está presente nas salas de aula apenas como apoio a outras disciplinas, desconsiderando-se aspectos específicos acerca da sua natureza artística. Este artigo, a partir de estudos de Larrosa (2003), Huizinga (1993) e Bordini e Aguiar (1993), analisa um projeto de literatura em que o leitor é o foco do processo, aplicado a estudantes de 8 o ano do Ensino Fundamental. O texto utilizado no projeto de leitura é Meninos do mangue, de Roger Mello (2001), construído por meio de uma narrativa de moldura e valendose da linguagem verbal e visual. O estudo sinaliza que a implementação da leitura literária por meio de uma proposta que acolhe o repertório e as expectativas do leitor pode ser um caminho que dá voz ao estudante, a fim de que exerça sua autoria, contribuindo para a sua educação estética.

PALAVRAS CHAVES: Leitura literária. Ensino Fundamental. Educação estética.

ABSTRACT

The presence of literary reading in schools, aimed at students' aesthetic education, is one of the objectives of the project Educação, Linguagem e Práticas Leitoras II (Education, Language and Reading Practices II) - UCS / CNPq - given the importance of literature for human formation. However, it is not a curricular component in basic education in Brazil and, in general, it is present in the classroom only as support for other disciplines, with specific aspects of an artistic nature being largely ignored. Based on the studies of Larrosa (2003), Huizinga (1993) and Bordini and Aguiar (1993), this paper examines a Literature project applied to students of the 8th year of the elementary school, in which the reader is the focus of the process. The text used in the reading project is Meninos do mangue, by Roger Mello (2001), constructed through the frame narrative and making use of verbal and visual language. The study indicates that 
the implementation of literary reading, through a proposal that includes the reader's repertoire and expectations, can be a means of giving voice to the student, in order to exercise his/her own authorship, and thereby contributing to his/her aesthetic education

KEYWORDS: Literary reading. Basic education. Aesthetic education.

Toda ação principia mesmo é por uma palavra pensada. Palavra pegante, dada ou guardada, que vai rompendo rumo.

(Guimarães Rosa)

INTRODUÇÃO

A Literatura abre caminhos para o pensamento e a sensibilidade do leitor, bem como para o convívio com expressões artísticas desde a infância que fortalecem a imaginação e o senso artístico e estético do humano. Os Parâmetros Curriculares Nacionais (1997, p. 19), explicitam que “[...] a arte ensina que é possível transformar continuamente a existência, que é preciso mudar referências a cada momento, ser flexível". O documento acrescenta que a flexibilidade e o acesso à arte são fundamentais para que se estabeleça a criação, a postura crítica e o aprendizado, principalmente numa época em que se prioriza o domínio da razão.

Por defender a presença da arte na formação humana, estudamos práticas leitoras de literatura no ambiente escolar. Práticas que priorizem a fruição, de modo que a interação com o texto no ambiente escolar contribua para a educação estética do aluno. Para tanto, os eixos artístico e estético sustentam este artigo. A obra literária é um objeto artístico, entendida como criação original, objeto/texto, capaz de "provocar uma atitude estética" (MUKAROVSKY, 1990, p. 117). Portanto, no caso da literatura infantil, o artístico pressupõe qualidades, veiculadas pela linguagem verbal e visual, as quais estão apresentadas e reconhecidas nesse objeto. Já o segundo, estético, envolve a relação que os sujeitos estabelecem com os objetos, num determinado espaço e tempo histórico, ou seja, implica a recepção desse produto. Almeja-se, assim, que, a partir de vivências planejadas e executadas intencionalmente com obras artísticas, a educação escolar propicie a educação estética aos estudantes.

Frente ao exposto, integrando as ações do projeto de pesquisa Educação, linguagem e práticas leitoras II, com apoio do CNPq, optamos por apresentar e discutir uma vivência de leitura literária na escola, intencionalmente planejada, visando contribuir para o letramento literário, aqui entendido como uma alternativa para chegar à educação estética. O objeto artístico, nesse caso, foram capítulos do livro Meninos do mangue, de Roger Mello (2001). A prática docente, planejada e executada para uma turma de sexto ano do Ensino Fundamental, propiciou a vivência de momentos especiais de interação com o texto literário e com os alunos. A experiência ocorreu unindo duas ações: uma pesquisa acadêmica e ações da disciplina de Prática de Ensino e Estágio Supervisionado em Língua Portuguesa e Literaturas de Língua Portuguesa. Desde o primeiro encontro - no total, foi desenvolvido com o texto um projeto de seis horas-aula com atividades de leitura e discussão - os estudantes demonstraram estar atentos. Mesmo os alunos tidos como mais "difíceis" participaram das atividades, muitas vezes, destacando-se entre os demais colegas pela criatividade de suas exposições. Pontuamos que o comportamento do grupo em relação aos textos literários foi bem distinto daquele observado frente aos textos não artísticos, já que, concomitantemente ao projeto de literatura, foram desenvolvidas ações que priorizaram o estudo da língua portuguesa, na mesma turma.

\section{PRÁTICA LEITORA}

O mangue, espaço ficcional da narrativa Meninos do mangue, de Roger Mello, onde se desenvolve a narrativa, é alheio à realidade dos alunos participantes desse estudo, os quais residem na região de Caxias do Sul-RS/Brasil, de modo que o espaço e os vários fatos narrados eram desconhecidos para os adolescentes. Essa característica do enredo poderia ter se constituído um obstáculo para a compreensão e a aceitação da obra. No entanto se constituiu como um fator de novidade e surpresa 
desvelado pelo texto.

O sucesso da vivência pode ser a atribuído a dois aspectos. Primeiro, a linguagem textual é comunicativa, atual e bem humorada. A obra é singular, inusitada, pelo enredo - a aposta e a contação de histórias entre a Sorte e a Preguiça - , pelo espaço - o mangue -, pela sua estrutura - narrativa de encaixe - e pela presença da visualidade. Em segundo lugar, os pressupostos teóricos, que embasaram a elaboração da unidade de ensino (COSSON, 2006; SARAIVA, 2001; BORDINI; AGUIAR, 1993), privilegiam a atuação do leitor frente às especificidades da obra literária, permitindo a exploração dessas características do texto, o que poderia não acontecer se o planejamento estivesse pautado em outros objetivos, como a análise gramatical, por exemplo, ou mesmo a leitura do texto artístico como pretexto para a realização de alguma atividade criativa, sem antes ter se apropriado do texto.

Esta experiência com a literatura em sala de aula destaca a abordagem da literariedade da obra e suscitou questionamentos sobre a natureza do texto no ato de recepção como: Que especificidades o texto literário possui para conquistar a atenção de alunos, até mesmo os mais "difíceis"? Como um texto aparentemente tão distante da realidade dos adolescentes pode encantá-los? Que experiência é vivida pela leitura da literatura?

Algumas "pistas" se apresentam para responder a essas questões. Observamos que a leitura literária mobilizou conhecimentos e vivências dos alunos e propiciou a ampliação desse repertório por meio da reconstrução do universo representado pela palavra, reconstrução que envolve o jogo com a linguagem e com o conhecimento de mundo do leitor. Nesse jogo, não estão envolvidos apenas habilidades e conceitos linguísticos, mas elementos culturais e pessoais dos leitores. Diante disso, a partir da análise do texto Meninos do mangue, este artigo busca investigar aspectos inerentes à natureza do texto literário, os quais propiciam ao leitor essas experiências, que contribuem para a educação estética, tornando a abordagem da literatura significativa para alunos e professores e indicando sua presença em nossas salas de aula. Para analisar o fenômeno, buscamos estudos de Larrosa (2003), Huizinga (1993) e Bordini e Aguiar (1993), entre outros.

\section{DANDO ASAS À IMAGINAÇÃO: O INUSITADO E A TRANSGRESSÃO}

A escolha do texto literário para a abordagem não foi aleatória. Entendemos que a literatura é transformadora de gente e, como defende Candido (1995), deveria ser um direito humano, um direito a ser colocado como acessível à criança desde sua concepção, na família, passando pela escola e seguindo pela vida adulta. O caráter simbólico contribui, principalmente, para a articulação de um dos papéis fundamentais do texto literário, que é, segundo Candido (1995, p. 245), o da humanização, ao afirmar: “Toda obra literária é antes de mais nada uma espécie de objeto, de objeto construído; e é grande o poder humanizador desta construção, enquanto construção". A narrativa escolhida discute conflitos humanos por meio da construção ficcional.

A palavra "personagem", segundo a etimologia indicada por Candido, tem origem na forma latina persona, termo que significa caráter, pessoa e também designa as máscaras utilizadas pelos atores no teatro grego. Aplicando a etimologia latina ao texto de Mello, podemos afirmar que sorte e preguiça, conceitos abstratos, adquirem caráter, personalidade própria e tornam-se agentes, personagens: a Sorte e a Preguiça. Ambas pescam siris no mangue quando resolvem fazer uma aposta: quem pesca o siri com mais patas. A Sorte pesca, mesmo sem isca, um siri com nove patas ( o siri é um animal de dez patas), e a Preguiça sai à procura de uma isca especial para pescar seu siri, com ares de vitoriosa. Entretanto, ao retornar, pesca um siri com oito patas, perdendo a aposta e corroborando a tradição popular, a qual ensina que quem tem sorte vence sempre e que a preguiça não conduz ao sucesso. Como vencedora, a Sorte determina que a Preguiça conte histórias, uma para cada pata do siri pescado e, em cada narrativa, ambas deveriam ser citadas, não necessariamente como personagens. Geralmente, a narradora, a Preguiça, participa de tais histórias como personagem, enquanto a Sorte apenas é mencionada. Dessa forma, a Preguiça passa a contar histórias conhecidas, vividas ou presenciadas por ela no mangue, enquanto procurava tripas de galinha - a isca preferida para pescar seu siri.

As histórias que a Preguiça conta, além de revelarem aspectos do cotidiano no mangue - a vida das crianças e das mulheres, por exemplo - também estabelecem um jogo de linguagem. Elementos de uma narrativa - personagens, lugares, situações - são utilizados como ponto de 
partida para outras histórias, sugerindo o encadeamento em que uma história pode anunciar outra e assim sucessivamente. Por exemplo, o robô encontrado pelos meninos no final de um capítulo reaparece em outro episódio, mais adiante, dando origem a uma nova narrativa. O aratu que tinha uma lua pintada nas costas, considerado por Josimar - um dos meninos do mangue - como o seu aratu da sorte, em um episódio, reaparece em outro nas mãos de Maria Cristina, que pinta a letra C com esmalte branco em seu casco. Enigmas postos numa história podem ser solucionados em outra. Dessa forma, o conflito que se passa entre a Sorte e a Preguiça é moldura para as histórias de moradores do mangue - seu Potó, J osimar, Dona Coisinha, Maria da Cabana... - , vidas e narrativas que se inter-relacionam, ressignificando-se mutuamente e revelando aspectos de uma cultura peculiar. Essa forma de construção constitui-se um desafio para o leitor, que precisa estar atento à linguagem e ao enredo, a fim de construir novas relações entre os elementos do texto.

Cabe-nos ainda destacar a interação entre as linguagens verbal e visual presentes na narrativa. $\mathrm{O}$ texto se constitui pela palavra e também pela visualidade. A relação entre seres humanos, siris, caranguejos e mangue é apresentada pelas duas linguagens. A seguir, podemos observar, na capa da obra, a profunda junção entre o mangue e seus moradores, sugerida não apenas pelo título, mas principalmente pela ilustração (Fig. 1). A imagem da capa já antecipa aspectos do enredo, tendo elementos culturais e naturais em simbiose, unidos e inter-relacionados, à frente de um fundo preto que representa o lodo do mangue. A simbiose proposta pela imagem é um traço do conflito em que pessoas misturam-se com pessoas, animais mesclam-se com humanos e as habitações parecem brotar do mangue.

Esses elementos sinalizam algumas características do texto que podem esclarecer a sedução dos alunos-leitores. A primeira delas é a subversão a convenções culturais. Quem imaginaria Sorte e Preguiça como pessoas? E ainda: quem imaginaria uma Sorte preguiçosa e uma Preguiça trabalhadeira que, embora um tanto lenta, procura isca para pescar, inventa e conta histórias? 0 texto as apresenta dessa forma, brincando com as concepções do leitor, partindo das mesmas para questioná-las e ampliá-las. A estrutura de Meninos do mangue também subverte, estabelecendo um jogo com a linguagem que desafia o leitor-jogador a encontrar e a solucionar "enigmas" linguísticos, modificando os padrões narrativos mais comuns ao construir redes de significados não lineares. Quem imaginaria, por exemplo, que a lua no casco do aratu, que fascina Josimar, é a mesma letra C pintada por Maria Cristina, ao pescar siris?

Entretanto, de que forma se estabelece esse jogo de significação? O jogo desenvolve-se, Fig. 1: Capa da obra Meninos do mangue, de Roger Mello (2001)

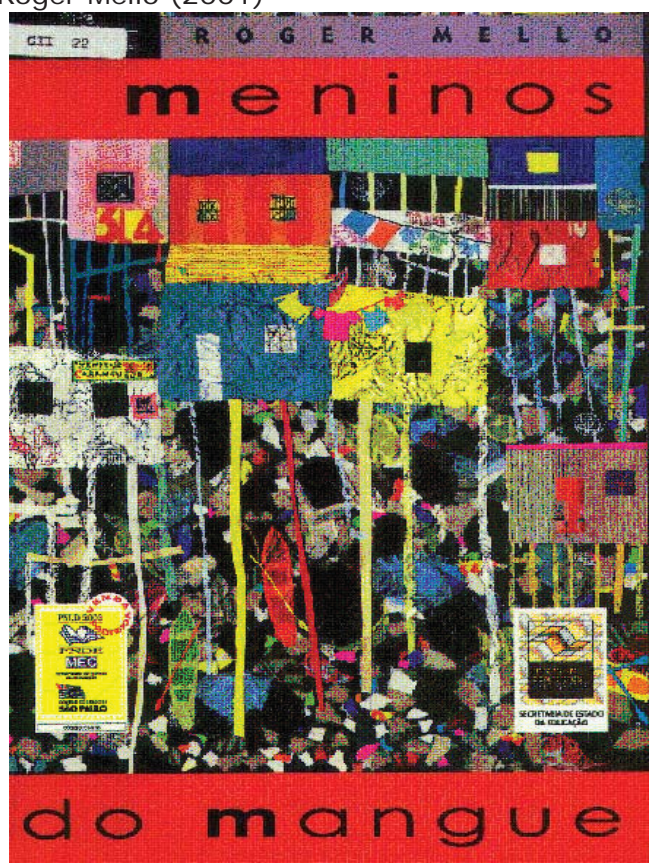

no texto literário, pelo ludismo, pela brincadeira com as palavras e as imagens produzidas pelas palavras, assim como entre esses elementos. Essa característica tão marcante na narrativa não é um privilégio da obra, mas elemento inerente à literatura, que ocorre de maneira mais ou menos intensa em todos os textos artísticos. Para Huizinga (1993, p. 133),

(...) a poiesis é uma função lúdica. Ela se exerce no interior da região lúdica do espírito, num mundo próprio para ela criado no espírito, no qual as coisas possuem uma fisionomia inteiramente diferente da que apresentam na "vida comum", e estão ligadas por relações diferentes das da lógica e da causalidade. (HUIZINGA, 1993, p. 133).

Para o autor, a poiesis - aqui entendida como criação que se manifesta na literatura - apoia-se na lógica "do sonho, do encantamento, do êxtase, do riso", elementos do plano primitivo e originário do ser humano, "a que pertencem a criança, o animal, o selvagem e o visionário" (HUIZINGA, 1993, p. 133). Ou seja, a literatura é concebida como um espaço privilegiado para a imaginação, a inventividade, a criatividade, a originalidade, a liberdade, a subversão... Como não poderia, então, seduzir adolescentes, sedentos de espaço para o novo, para a criação, para a irreverência? 
A exploração do inusitado, essa transgressão ao convencional, vivida na leitura literária, não apenas vai ao encontro de uma necessidade humana, mais evidente no público adolescente - possível leitor dessa obra -, mas também possibilita a construção de conhecimento. Ao apresentar o novo e instigar a criatividade do leitor, a literatura possibilita a reflexão sobre o que foi convencionado como realidade. De acordo com Cosson (2006, p. 16), “a prática da literatura, seja pela leitura, seja pela escritura, consiste exatamente em uma exploração das potencialidades da linguagem, da palavra e da escrita, que não tem paralelo em outra atividade humana". Dessa forma, o texto literário atrai e desafia os leitores, enriquecendo suas vivências e abrindo novos horizontes. É "o dizer o mundo (re)construído pela força da palavra" (COSSON, 2006, p. 16).

Temas como a vida no mangue podem se tornar literários, desde que sofram um tratamento adequado. A novidade no modo de dizer, seja pela estrutura, seja pelo emprego da linguagem, põe em evidência o caráter polissêmico da literatura, a qual é concebida por Bordini e Aguiar (1993, p. 17) como "um campo de plena liberdade para o leitor, o que não ocorre em outros textos. Daí provém o próprio prazer da leitura, uma vez que ela mobiliza mais intensa e inteiramente a consciência do leitor, sem obrigá-lo a manter-se nas amarras do cotidiano". Ler Meninos do mangue desafia o interlocutor, que constrói significados para o texto e a partir do texto. Ler a narrativa como experiência possibilita que a história não apenas seja significada pelo leitor, mas que o leitor se revisite, se ressignifique a partir das inquietações propostas pelo texto, contribui para a educação estética do sujeito. A poiesis, entendida como um ato de criação, presente na organização do livro formado por duas linguagens, estende-se, pois, ao ato de ler, no qual cada sujeito exercita seu poder de criar sentidos para a narrativa, a partir dos elementos postos pelo autor, na palavra e na ilustração. Além disso, a leitura propicia que o leitor signifique a si mesmo a partir da experiência posta pela ficção.

A riqueza e a beleza do texto motivaram sua escolha para a organização de uma unidade de ensino dirigida a uma turma de estudantes cuja idade está em torno dos 13 anos. A ausência da disciplina Literatura no currículo do Ensino Fundamental possibilitou que elegêssemos a abordagem de nossa preferência, conforme proposição da professora titular, já que não havia conteúdos específicos da disciplina no programa da série. Escolhido o texto, passamos ao processo de organização da unidade ensino para as seis aulas. O macroplanejamento foi organizado a partir do método recepcional, conforme proposição de Bordini e Aguiar (1993). O método, baseado em estudos da Estética da Recepção, determina uma sequência de etapas a serem propostas na abordagem da literatura. Inicialmente, deve ocorrer a determinação do horizonte de expectativas, a fim de conhecer os interesses, as necessidades e o conhecimento do grupo a que se vai atender. Esse levantamento foi realizado por meio da aplicação de um questionário de múltipla escolha, no qual os alunos informavam sobre suas vivências, hábitos e preferências de leitura, não apenas de textos literários.

O momento seguinte envolve o atendimento do horizonte de expectativas, realizado, nesse caso, por meio da proposição de um jogo dramático. Nesta atividade, os alunos, em grupos, receberam palavras com as letras embaralhadas ("sorte" e "preguiça"), discutiram seu sentido e apresentaram as ideias levantadas sobre os temas, por meio de encenações. Nesse momento, tínhamos como objetivo levantar as concepções prévias dos alunos sobre os assuntos propostos, que fazem parte da narrativa Meninos do mangue, de forma divertida e atraente, adequada aos seus interesses e aos seus gostos.

A seguir, propusemos a ruptura do horizonte de expectativas. Essa etapa foi realizada pela apresentação da obra, envolvendo a capa e os dados sobre o autor, e de três capítulos do texto (xerocados, porque não havia nenhum exemplar na escola; e os estudantes não têm o hábito de comprar livros), intitulados "Maré alta" (2001, p. 11-14), "Você sabe o que é aratu" (2001, p. 20-23) e "História à toa, sem importância" (2001, p. 30-33). Após a leitura de cada capítulo, foram propostas atividades orais e escritas, objetivando a percepção e a significação de elementos linguísticos desses excertos, com ênfase na interação entre linguagens, na estrutura de narrativa de encaixe e na atuação do narrador.

Na abordagem recepcional, também está previsto o questionamento do horizonte de expectativas, que consiste na comparação entre o horizonte inicial atendido e a nova proposta apresentada no momento de ruptura, seguido pela ampliação desse horizonte, decorrente da comparação entre os horizontes, inicial e atual e pela tomada de consciência das alterações e das aquisições. Essas etapas foram implementadas por meio de discussões orais sobre a aprendizagem decorrente da leitura e a significação dos textos, sistematização dos novos conhecimentos e a produção de uma narrativa, 
em duplas, que se passasse em uma realidade distinta da vivida pelos alunos, a exemplo do texto Meninos do mangue. Nessa produção, os alunos deveriam aplicar recursos narrativos estudados na obra de Roger Mello, além de outros já conhecidos, a fim de atender aos objetivos da tarefa.

Para o microplanejamento, ou seja, para a abordagem de cada um dos textos selecionados, foi organizado um roteiro de leitura conforme orientações de Saraiva (2001). A autora propõe que a leitura literária constitua-se em três etapas: (a) introdução à recepção do texto, (b) leitura compreensiva e interpretativa, (c) transferência e aplicação de leitura. A motivação, correspondente ao momento de introdução, constitui uma estratégia ou atividade que visa estimular e sensibilizar o aluno para a leitura do texto. A leitura compreensiva e interpretativa caracteriza-se por propostas que permitam a "apreensão do horizonte inscrito no texto, do qual o receptor faz parte" (SARAIVA, 2001, p. 86), ou seja, destina-se à percepção e à atribuição de sentido aos elementos do texto, pelo leitor, a partir de sua vivência e conhecimento. A transferência e a aplicação de leitura, finalmente, possibilitam ao aluno produzir seus próprios textos por meio de ações e linguagens variadas; constitui, enfim, a realização de atividades a partir da leitura e da discussão da obra. Esse momento permite ao leitor atualizar o conhecimento construído na interação com o texto, "já que o circuito da comunicação literária instala uma interação dialética que impele o receptor a se transformar em emissor de novas mensagens" (SARAIVA, 2001, p. 86).

A título de exemplificação, descrevemos brevemente a operacionalização dessas etapas, realizada em uma aula de dois períodos conjugados, a partir do segundo texto, intitulado "Você sabe o que é aratu?" (2001, p. 20-23). Como introdução à leitura, o título do capítulo foi apresentado, sem que os alunos tivessem contato com o texto, e a questão lançada foi dirigida ao grupo: o que é aratu? No contexto da obra que estamos lendo, o que poderia ser aratu? O que não poderia ser? Por quê? Nesse momento, buscamos estimular a curiosidade dos adolescentes e retomar aspectos abordados nas aulas anteriores, a fim de criar um ambiente propício à próxima leitura. A seguir, a professora leu o texto para os alunos, que acompanharam a leitura em fotocópias.

A leitura compreensiva e interpretativa envolveu a análise do capítulo lido, orientada e instigada por questões norteadoras propostas pela docente, e a discussão dos elementos observados e dos significados atribuídos ao texto pelo grupo. Nesse capítulo, as perguntas voltaram-se ao foco narrativo, ampliando o que fora abordado na leitura anterior, a saber: a caracterização do espaço e dos personagens, o vocabulário regional empregado, a interação entre palavra e ilustração e a narrativa de encaixe, buscando a percepção dos mecanismos de construção desses elementos e significando-os. Essa perspectiva pode ser observada na questão a seguir, proposta na interpretação: “A ilustração da página 22 (Fig. 2) também contribui para a caracterização do ambiente. Observando essa imagem, responda: (a) A partir das cores utilizadas, linhas de contorno, disposição dos seres e sua configuração, como a imagem representa o mangue e os meninos?; (b) Que relações podem ser estabelecidas entre o mangue e os meninos?" A atividade procura orientar a percepção do aluno e auxiliá-lo a estabelecer aproximações entre os constituintes da obra, a fim de significá-los.

A transferência e a aplicação de leitura, etapa final proposta por Saraiva (2001) na organização de roteiros, foi organizada de forma diversa na unidade de ensino. Propusemos apenas uma atividade de transferência, ao final da leitura dos três textos, incluindo elementos comuns às três análises. Essa atividade contou com a produção de

Fig. 2 - A vida no mangue. Fonte: Mello (2001, p. 22)

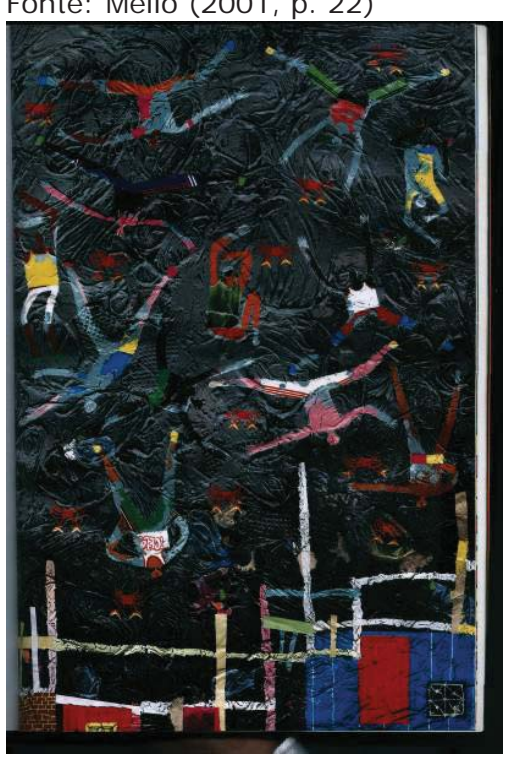
narrativa, descrita anteriormente, neste estudo, como uma das estratégias de ampliação do horizonte de expectativas dos alunos. Dessa forma, as orientações de Saraiva (2001) e Bordini e Aguiar (1993) nortearam o trabalho desenvolvido, mas foram reorganizadas e adequadas de forma a atender aos objetivos da unidade e às necessidades dos alunos. Entendemos que pressupostos teóricos e metodológicos estão a serviço da aprendizagem e não podem engessar a prática do professor. A metodologia adotada propiciou aos alunos e às 
professoras envolvidos, a partir do estudo da composição do texto, a fruição do texto e a ampliação do seu conhecimento linguístico e de mundo. A seguir, refletiremos sobre o modo como o ato de conhecer permeia a leitura e se constrói por meio dela.

\section{LITERATURA COMO PRODUTORA DE CONHECIMENTO}

Além do ludismo e da irreverência, o que mais os leitores-adolescentes podem ter encontrado em Meninos do mangue? Já mencionamos que a construção literária, entendida como artística, encerra uma seriedade e é produtora de conhecimento, conforme Huizinga (1993). Entretanto que conhecimento poderia ser esse? A discussão sobre que tipo de conhecimento é gerado pela literatura e as formas como esse processo de conhecer se dá em cada indivíduo ainda estão abertas. Apesar disso, nos propomos a destacar alguns aspectos evidentes na obra de Roger Mello, sem a pretensão de esgotar o estudo.

Como já foi dito, Meninos do mangue apresenta, a partir da história da Sorte e da Preguiça, narrativas que se passam no mangue, envolvendo seus moradores. Dessa forma, a leitura da obra permite aos leitores conhecer - ou reconhecer - aspectos sociais, culturais e econômicos do contexto referido. Para Bordini e Aguiar,

(...) a atividade do leitor de literatura se exprime pela reconstrução, a partir da linguagem, de todo o universo simbólico que as palavras encerram e pela concretização desse universo com base nas vivências pessoais do sujeito. A literatura, desse modo, se torna uma reserva de vida paralela, onde o leitor encontra o que não pode ou não sabe experimentar na realidade. (BORDINI; AGUIAR, 1993, p. 15).

Nessa perspectiva, o texto literário possibilita ao leitor vivenciar contextos diferentes do seu, reconstruídos, nesse caso, pela palavra e pela ilustração. Essas experiências ampliam a compreensão do mundo, do outro e de si mesmo, ou seja, geram não só conhecimento, mas autoconhecimento. Segundo Cosson,

(...) na leitura e na escritura do texto literário encontramos o senso de nós mesmos e da comunidade a que pertencemos. A literatura nos diz o que somos e nos incentiva a desejar e a expressar o mundo por nós mesmos. E isso se dá porque a literatura é uma experiência a ser realizada. É mais que um conhecimento a ser reelaborado, ela é a incorporação do outro em mim sem renúncia da minha própria identidade. (COSSON, 2006, p. 17).

Ao conhecermos novas "realidades inventadas", estabelecemos identificações e divergências em relação ao outro, processos que esclarecem ao sujeito a compreensão de si mesmo e de seu próprio contexto. Esses movimentos de "ser" e "não ser" ajudam a definir a própria identidade, seja como sujeito, seja como grupo social. Talvez a história ambientada num cenário desconhecido pelos alunos, mas apresentando conflitos humanos similares aos que vivem, tenha sido um fato de identificação com a narrativa e uma possibilidade de repensar sobre si mesmo.

Para Larrosa (2003), a compreensão de si mesmo e, consequentemente, dos outros, tem como um de seus mecanismos fundamentais a própria estrutura narrativa. "El sentido de quién somos es análogo a la construcción y la interpretación de um texto narrativo y, como tal, obtiene su significado tanto de las relaciones de intertextualidad que mantiene com otros textos como de su funcionamiento pragmático em um contexto"2

(LARROSA, 2003, p. 608). Para o autor, a construção da identidade como processo narrativo é influenciada pelas histórias que ouvimos - narrativas literárias, narrativas sobre si mesmo e narrativas sobre outras pessoas. Nesse sentido, podemos perceber a importância da abordagem de textos literários nas escolas e também fora da escola, já que os mesmos contribuirão para a autoconsciência do indivíduo.

Além da construção da identidade, a literatura proporciona a reflexão sobre a própria condição do ser humano no mundo, ou seja, sobre os elementos universais ao homem, independentemente de sua condição particular, já que a

[...] linguagem literária extrai dos processos histórico-político-sociais nela representados uma visão típica da existência humana. O que importa não é apenas o fato sobre o qual se escreve, 
mas as formas de o homem pensar e sentir esse fato, que o identificam em outros homens de tempos e lugares diversos (BORDINI, AGUIAR, 1993, p. 14).

Essa identificação com outros indivíduos, proporcionada pela leitura literária, é outro elemento sedutor na obra de Roger Mello. Embora o mangue seja uma realidade distante dos alunos que leram o texto, há aspectos na obra que são compartilhados com os leitores da Serra Gaúcha: as relações de poder, a desonestidade, a sorte, as relações amorosas, a amizade, a cooperação, a persistência, a teimosia... Esses e outros tantos aspectos presentes no texto tocam leitores de contextos distintos, porque os identificam em uma mesma situação: a existência humana, plena de incertezas, dicotomias e ambiguidades. Essa gama de emoções está presente e potencializada na literatura, de modo que a leitura do texto propicia uma experiência estética.

\section{CONSIDERAÇÕES FINAIS}

A escolha da obra literária que constituirá objeto de estudo e das estratégias de mediação para efetivar a leitura como experiência é decisiva para o sucesso da leitura. Obra e dinâmicas de leitura devem contribuir para iluminar e enriquecer o mundo criado pela imaginação - gerando e vivendo realidades diversas -, esse "tornar o mundo compreensível" (COSSON, 2006, p. 17) por meio do ludismo das palavras talvez explique a enorme atração que o texto literário exerceu sobre os alunos adolescentes durante a situação de sala de aula. Mais do que isso, confirma e reafirma a posição de inúmeros teóricos - entre eles Larrosa, Cosson, Bordini e Aguiar, citados neste artigo - sobre a importância de um trabalho competente com o texto literário em nossas escolas. Nesse ponto, tocamos em um aspecto delicado da realidade educacional, em especial, a brasileira: a ausência de ações planejadas e sistemáticas de leitura literária nas salas de aula da Educação Básica. Parece que a inexistência da disciplina como componente curricular individualizado implica, em geral, o desaparecimento do texto literário na escola, justamente aquele texto que, pela linguagem figurada e pelas temáticas, muito pode contribuir para que o leitor conheça o seu entorno e a sim mesmo, a partir da leitura, ampliando e enriquecendo seu campo de vivências.

Embora o texto literário desperte grande interesse de leitura, como pode ser constatado não apenas na situação relatada neste estudo, mas em qualquer experiência com a literatura, observamos que a abordagem da literatura restringe-se a trabalhos isolados ou ao estudo da história da literatura, pautado em períodos literários. Enquanto a perspectiva histórica da literatura predomina no Ensino Médio, no Fundamental observamos que, geralmente, o texto literário é utilizado como pretexto para o ensino de conteúdos escolares (temas transversais, análise gramatical, entre outros), normas e atitudes ou ainda para propiciar a realização de atividades ditas criativas. Assim, uma narrativa é lida e, equivocadamente, se confecciona uma maquete a partir do cenário, ou modifica-se o final da história, sem estudar a coerência interna no texto ou outros aspectos inerentes à sua composição, de modo a instrumentalizar o leitor para ser coautor do texto. Dessa forma, a lista se estende além da nossa imaginação e provavelmente da sua. A fruição do texto literário é uma realidade pouco presente em nossas salas de aula.

Diante disso, assim como Morin (2004), defendemos a reintrodução da "cultura das humanidades" - literatura, poesia, cinema, psicologia, filosofia - nos currículos, como uma forma de superar a fragmentação dos saberes, que atualmente rege nosso sistema educacional. Essa fragmentação, de acordo com o autor, precisa ser substituída por uma proposta pautada na complexidade, capaz de dar conta do contexto em que vivemos. Nessa perspectiva, "literatura, poesia e cinema devem ser considerados não apenas, nem principalmente, objetos de análises gramaticais, sintáticas ou semióticas, mas também escolas de vida, em seus múltiplos sentidos" (MORIN, 2004, p. 48, grifo do autor). Se a escola oportuniza aprendizagens para a vida, para a humanização dos estudantes, temos que inserir a literatura no currículo escolar e, mais, respeitar a sua natureza polissêmica. Atrelada a cada texto literário está uma determinada cultura, que oferece aos leitores conhecimentos novos. No caso da aplicação da unidade elaborada para a obra Meninos do mangue, os exercícios finais, referentes a cada um dos textos, sinalizam que houve apropriação e transformação dos aspectos culturais presentes no texto. Elementos da cultura do mangue foram transpostos a outros ambientes culturais conhecidos pelos alunos, referendando que a literatura no currículo contribui para a formação cultural do aluno. 
Pesquisadores, supervisor, professor-estagiário e estudantes puderam vivenciar essa experiência da literatura com uma escola de vida que contribui para a educação estética. Os momentos mostraramse prazerosos e significativos para todos, revelando a importância e a eficácia da abordagem da literatura em sala de aula, respeitando e explorando as especificidades e as potencialidades do texto literário. É urgente que outros profissionais percebam essa riqueza e se utilizem dela, a fim de que os alunos não sejam privados da fruição e, consequentemente, educação estética, possível pela vivência da leitura literária e da formação humana proporcionada por essa experiência. Só assim a palavra literária torna-se "palavra pegante", como afirma Guimarães Rosa, que vai se antecipando a nós mesmos, de forma que "estamos sendo" constituídos pela palavra dos outros, que passa a ser também nossa. Assim, nos enredamos nos enredos e os vivemos. Como humanos que somos, temos direito à arte, nesse caso, à literatura e, para que esse direito seja pleno, receber na escola também educação estética.

\section{REFERÊNCIAS}

BORDINI, Maria da Glória; AGUIAR, Vera Teixeira de (1993). Literatura: a formação do leitor: alternativas metodológicas. 2. ed. Porto Alegre: Mercado Aberto.

BRASIL. PARÂMETROS CURRICULARES NACIONAIS: introdução aos parâmetros curriculares nacionais. Secretaria de Educação Fundamental. Brasília: MEC/SEF, 1997. Disponível em: http://portal.mec.gov.br/ seb/arquivos/pdf/livro06. pdf. Acesso em: $1^{\circ}$ de Março de 2012.

CANDIDO, Antônio. Vários escritos. São Paulo: Duas cidades, 1995.

COSSON, Rildo (2006). Letramento literário: teoria e prática. São Paulo: Contexto.

HUIZINGA, J ohan (1993). Homo ludens. São Paulo, Perspectiva.

LARROSA, Jorge (2003). La experiencia de la lectura: estudios sobre literatura e formación. México: FCE.

MELLO, Roger (2001). Meninos do mangue. São Paulo: Companhia das Letrinhas.

MORIN, Edgar (2004). A cabeça bem-feita: repensar a forma, reformar o pensamento. 9. ed. Rio de Janeiro: Bertrand Brasil.

MUKAROVSKY, Jan. Escritos sobre estética e semiótica da arte. Lisboa: Editoria Estampa, 1990.

SARAIVA, Juracy Assmann (Org.) (2001). Literatura e alfabetização: do plano do choro ao plano da ação. Porto Alegre: Artmed.

ROSA, J oão Guimarães (1976). Grande sertão: veredas. 10. ed. Rio de Janeiro: J osé Olympio.

NOTAS

1 Este artigo foi produzido no contexto da pesquisa Educação, linguagem em práticas leitoras II, na Universidade de Caxias do Sul, com apoio do Edital MCT/CNPq/MEC/CAPES no 02/2010 - Ciências Humanas, Sociais e Sociais Aplicadas.

2 O sentido de quem somos é análogo à construção e à interpretação de um texto narrativo e, como tal, obtém seu significado tantos das relações de intertextualidade que mantém com outros textos como de seu funcionamento pragmático em um contexto (tradução nossa).

Artigo recebido em 31/07/2012

Aprovado em 04/09/2012 